\title{
Clinical and cost effectiveness of switching asthma patients from fluticasone-salmeterol to extra-fine particle beclometasone-formoterol: a retrospective matched observational study of real-world patients
}

\section{*David Price, ${ }^{1,2}$, lain Small ${ }^{3}$, John Haughney1, Dermot Ryan ${ }^{4}, K^{1}$ evin Gruffydd-Jones ${ }^{5}$, Federico Lavorini ${ }^{6}$, Tim Harris ${ }^{7}$, Annie Burden², Jeremy Brockman², Christine King ${ }^{2}$, Alberto Papi ${ }^{8}$}

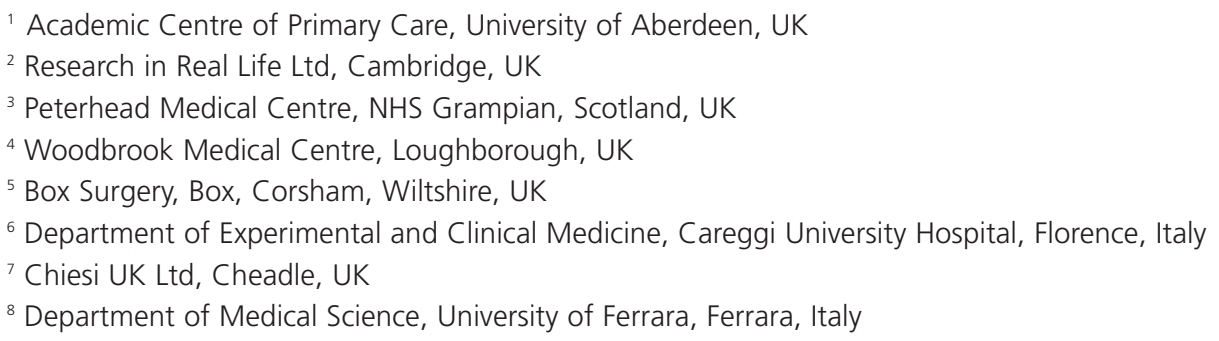

Received 18th June 2013; revised 15th September 2013; accepted 16th September 2013; online 2nd November 2013

\begin{abstract}
Background: Efficacy trials suggest that extra-fine particle beclometasone dipropionate-formoterol (efBDP-FOR) is comparable to fluticasone propionate-salmeterol (FP-SAL) in preventing asthma exacerbations at a clinically equivalent dosage. However, switching from FP-SAL to efBDP-FOR has not been evaluated in real-world asthma patients.

Aims: The REACH (Real-world Effectiveness in Asthma therapy of Combination inHalers) study investigated the clinical and cost effectiveness of switching typical asthma patients from FP-SAL to efBDP-FOR.

Methods: A retrospective matched (1:3) observational study of 1,528 asthma patients aged 18-80 years from clinical practice databases was performed. Patients remaining on FP-SAL $(n=1,146)$ were compared with those switched to efBDP-FOR at an equivalent or lower inhaled corticosteroid (ICS) dosage $(n=382)$. Clinical and economic outcomes were compared between groups for the year before and after the switch. Non-inferiority (at least equivalence) of efBDP-FOR was tested against FP-SAL by comparing exacerbation rates during the outcome year.

Results: efBDP-FOR was non-inferior to FP-SAL (adjusted exacerbation rate ratio 1.01 (95\% Cl 0.74 to 1.37 )). Switching to efBDP-FOR resulted in significantly better $(\mathrm{p}<0.05)$ odds of achieving overall asthma control (no asthma-related hospitalisations, bronchial infections, or acute oral steroids; salbutamol $\leq 200 \mu \mathrm{g} /$ day) and lower daily short-acting $\beta_{2}$-agonist usage at a lower daily ICS dosage (mean $-130 \mu \mathrm{g} /$ day FP equivalents; $p<0.001)$. It also reduced mean asthma-related healthcare costs by $f 93.63 /$ patient/year $(p<0.001)$.

Conclusions: Asthma patients may be switched from FP-SAL to efBDP-FOR at an equivalent or lower ICS dosage with no reduction in clinical effectiveness but a significant reduction in cost.

(C) 2013 Primary Care Respiratory Society UK. All rights reserved.

D Price et al. Prim Care Respir J 2013; 22(4): 439-448

http://dx.doi.org/10.4104/pcrj.2013.00088
\end{abstract}

Keywords asthma, extra-fine particle, beclometasone, formoterol, fluticasone, salmeterol

\footnotetext{
* Corresponding author: Professor David Price, Academic Centre of Primary Care, University of Aberdeen, Polwarth Building, Foresterhill, Aberdeen AB25 2ZD, UK. Tel: +44 (0)1224 554588 Fax: +44 (0)1224 550683 E-mail: david@respiratoryresearch.org
} 
The full version of this paper, with online appendices,

is available online at www.thepcrj.org

\section{Introduction}

Asthma is a complex and costly disease to manage, particularly in patients with moderate-to-severe persistent asthma who require combination therapy with an inhaled corticosteroid (ICS) and longacting $\beta_{2}$-receptor agonist (LABA) for daily asthma control. For example, in the East of England, a region of approximately 5.85 million people, ${ }^{1}$ the Strategic Health Authority reported in 2011 that

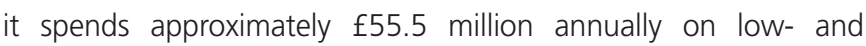
moderate-dose combination ICS-LABA inhalers. ${ }^{2}$ Any measure that reduces the cost of asthma therapy without reducing the effectiveness or increasing the risk is therefore worthy of consideration.

In January 2008 an extra-fine particle formulation of beclometasone dipropionate (efBDP) and formoterol (FOR) was licensed in the UK as a fixed-dose combination (FDC) inhaler for use in the treatment of asthma in adults. ${ }^{3}$ Extra-fine particle BDP-FOR has several advantages over larger particle ICS-LABA combinations such as fluticasone propionate and salmeterol (FP-SAL), the efBDP and FOR components each contributing a clinical advantage.

First, pulmonary distribution - especially to the small airways - is greater for extra-fine particle formulations than for larger particle formulations. . $^{413}$ Second, and no doubt consequentially, efBDP is as effective for asthma control as larger particle ICS formulations, at a lower ICS dosage. For example, the clinical equivalence of efBDP and FP in asthma patients can be described as a ratio of approximately $0.8: 1$, so $400 \mu \mathrm{g}$ of efBDP is clinically equivalent to $500 \mu \mathrm{g}$ of FP. ${ }^{12-15} \mathrm{~A}$ third and probably related advantage is that extrafine particle inhalers may be less dependent on good inhaler technique - or more tolerant of poor technique - than larger particle formulations. ${ }^{7,16,17}$ Lastly, formoterol relieves bronchoconstriction more quickly than salmeterol ${ }^{18,19}$ and almost as quickly as shortacting $\beta_{2}$-receptor agonists (SABA) such as salbutamol, ${ }^{19-21}$ potentially improving patient compliance and allowing the efBDPFOR inhaler to be used for both maintenance and reliever therapy (MART) if the patient and physician elect this approach. ${ }^{22}$

In various studies, efBDP-FOR was at least as effective at improving lung function and measures of asthma control while preventing acute asthma exacerbations as (1) larger particle BDP with FOR delivered via separate inhalers; ${ }^{23}$ (2) FP-SAL; ;2-16,24,25 and (3) budesonide with formoterol (BUD-FOR). 16,24,26,27 As further evidence, in studies of ICS alone, efBDP was at least as effective for asthma control as larger particle formulations of $\mathrm{BDP}^{28-30}$ and fluticasone. ${ }^{31}$ However, the greater clinical effectiveness of efBDP may have been understated in efficacy studies involving randomised controlled trials (RCTs), which have shown no clear clinical advantage of any one ICS. ${ }^{32-34}$ In real-world asthma patients, efBDP provides equivalent and, in some cases, better - asthma control at a lower daily ICS dosage, ${ }^{31,35}$ and therefore lower risk for adverse effects ${ }^{31}$ and lower asthma-related healthcare costs ${ }^{35}$ - attributes considered important by physicians and respiratory specialists alike when choosing an ICSLABA combination. ${ }^{36}$
Product approval for the efBDP-FOR inhaler was granted in the UK based on RCTs in Europe which showed non-inferiority in morning pre-dose peak expiratory flow and no significant difference in the number of symptom-free days or adverse events, including acute exacerbations, compared with FP-SAL ${ }^{15}$ and BUD-FOR. ${ }^{26}$ Because efBDP-FOR costs less than other FDC inhalers and has been shown to be of comparable efficacy in asthma management, the UK National Health Service (NHS) in some regions encouraged physicians to switch patients to the efBDP-FOR inhaler in an effort to lower the costs of ongoing ICS-LABA therapy. ${ }^{2}$ This switch was estimated to save between $\mathrm{f3}$ and $\mathrm{f} 16$ per patient per month (depending on the inhaler) for low- and moderate-dose ICS-LABA therapy. ${ }^{2}$

However, despite the reasonable assumption of greater cost effectiveness with the efBDP-FOR inhaler, to date no studies have investigated the outcome of such a switch under real-world conditions of use. The clinical efficacy of switching from FP-SAL to efBDP-FOR, with ${ }^{14}$ or without ${ }^{25}$ a step-down in ICS dosage, has been shown in two recent RCTs, but it has yet to be demonstrated under less controlled conditions.

We therefore undertook a retrospective study of typical asthma patients seen in routine clinical practice in the UK, investigating both the clinical and cost effectiveness of switching from FP-SAL to efBDP-FOR at an equivalent or lower ICS dosage. Using nationwide patient databases, we sought to generate as large and representative a population of asthma patients as possible given the study aims, including patients with significant co-morbidities, a past or current smoking habit, and less than ideal adherence to their ICS prescriptions.

Our aims were twofold: (1) to determine whether efBDP-FOR is at least equivalent (non-inferior) to FP-SAL for exacerbation prevention when typical asthma patients are switched from FP-SAL to efBDP-FOR; and (2) to determine whether switching from FP-SAL to efBDP-FOR is cost-effective or represents a trade-off (lower cost but lower effectiveness).

\section{Methods}

\section{Study design}

A retrospective matched observational study was conducted of asthma patients in the UK treated in primary care practice. An outline of the study design is illustrated in Figure 1. For each patient meeting the inclusion criteria, the medical record was examined for 12 months before ('baseline year') and for 12 months after ('outcome year') the face-to-face or electronic review during which the physician either continued FP-SAL inhaler therapy at the same ICS dosage or switched the patient to efBDP-FOR at an equivalent or lower ICS dosage. The date of this pivotal patient review was designated the index prescription date (IPD). For further explanation, see Supplemental Materials (Appendix 1 available online at www.thepcrj.org).

Raw data were obtained from the UK Optimum Patient Care Research Database (http://www.optimumpatientcare.org/ Html_Docs/OPCRD.html) and the Clinical Practice Research Datalink, formerly known as the General Practice Research Database 


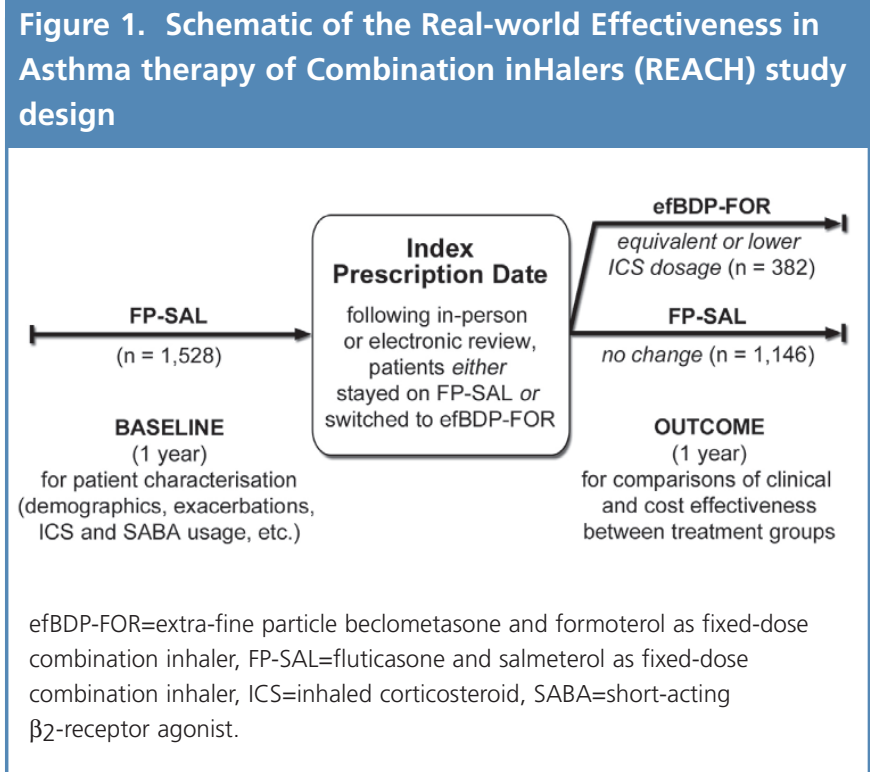

Box 1. Inclusion criteria for the Real-world Effectiveness in Asthma therapy of Combination inHalers (REACH) study

Age: $18-80$ years

Diagnostic code: asthma; no code for chronic obstructive pulmonary disease or other chronic respiratory condition (except asthma)

Smoking status: known

Baseline fluticasone and salmeterol as fixed-dose combination inhaler (FP-SAL) therapy: $\geq 2$ prescriptions for FP-SAL during baseline year

Oral steroids: none for maintenance during baseline year

Evidence of continuing therapy: $\geq 2$ prescriptions for extra-fine particle beclometasone and formoterol as fixed-dose combination inhaler (efBDP-FOR) during outcome year (efBDP-FOR group); no change in therapy (FP-SAL group)

Evidence of switching for reasons other than efficacy: $\geq 5$ patients in a practice switched from FP-SAL to efBDP-FOR, with no increase in inhaled corticosteroid dosage, in a 3-month period

(http://www.cprd.com/intro.asp), spanning the period from January 2007 to August 2012. Inclusion criteria are summarised in Box 1 and further details are given in the online Supplemental Materials, along with a CONSORT diagram illustrating the patient selection process (Figure S1). A total of 50,261 patients met the inclusion criteria, of whom 390 were switched to efBDP-FOR and 49,871 remained on FP-SAL.

The patients switched to efBDP-FOR were then matched as closely as possible in a ratio of 1:3 with those remaining on FP-SAL using the demographic and clinical criteria summarised in Table 1. Using a one-sided test of equivalence based on exacerbation prevention, the 1:3 ratio yielded a statistical power of $95 \%$ whereas lesser ratios yielded lower powers (93\% and $86 \%$ for $1: 2$ and $1: 1$ ratios, respectively). A time-frame of \pm 2 years for the IPD was
Table 1. Matching criteria for the Real-world

Effectiveness in Asthma therapy of Combination inHalers (REACH) study

\begin{tabular}{|c|c|}
\hline Criteria & Specifics \\
\hline Age & $\begin{array}{l} \pm 5 \text { years, within two subgroups: } \\
18-60 \text { years and } 61-80 \text { years }\end{array}$ \\
\hline Gender & Male or female \\
\hline Smoking status & $\begin{array}{l}\text { Non-smoker, current smoker, } \\
\text { or ex-smoker }\end{array}$ \\
\hline $\begin{array}{l}\text { Last prescribed ICS dosage } \\
\text { prior to IPD }\end{array}$ & Exact match ( $\mu \mathrm{g} /$ day $)$ \\
\hline $\begin{array}{l}\text { Type of consultation/review } \\
\text { at IPD }\end{array}$ & Face-to-face or electronic \\
\hline $\begin{array}{l}\text { Last ICS device prescribed } \\
\text { prior to IPD }\end{array}$ & MDI or DPI \\
\hline $\begin{array}{l}\text { Number of courses of acute } \\
\text { oral steroids }\end{array}$ & 0,1, or $2+$ \\
\hline $\begin{array}{l}\text { SABA usage, average } \\
\text { daily dose }\end{array}$ & $0,1-200,201-400,401-800,801+\mu \mathrm{g}$ \\
\hline Year of IPD & Closest match within \pm 2 years \\
\hline
\end{tabular}

deemed optimal for case matching, as a longer interval would have risked placing matched patients in different time periods and a shorter interval would have excluded too many otherwise eligible patients. As it was, eight patients in the efBDP-FOR group were excluded for unmatched data (see Figure S2 in online Supplemental Materials), so the final group numbers were 382 patients switched to efBDP-FOR and 1,146 patients remaining on FP-SAL for the outcome year.

\section{Clinical outcome measures}

The primary clinical outcome investigated was the incidence of severe asthma exacerbations, as defined by the American Thoracic Society and European Respiratory Society (ATS/ERS) task force on asthma control and exacerbations, where an exacerbation is defined as an occurrence of asthma-related hospital attendance/admission (including Accident and Emergency attendance) or the use of acute oral steroids. ${ }^{37}$ The secondary outcomes investigated are described in Table 2.

\section{Economic outcome measures}

Health economic analyses comprised comparisons of asthma-related healthcare costs and assessment of the cost effectiveness of treatment, using exacerbation prevention (ATS/ERS definition) and risk domain asthma control (see Table 2) as measures of treatment effectiveness.

Asthma-related costs included all asthma drug prescriptions: ICS of all kinds including FDC inhalers, oral corticosteroids for acute control, SABA, LABA, leukotriene receptor antagonists, theophylline, and antibiotics prescribed for lower respiratory tract infections. Drug costs were obtained from the 2010 British National Formulary (http://www.bnf.org/bnf/index.htm).

Asthma-related costs also included general practitioner (GP) consultations and respiratory-related hospitalisation costs 
Table 2. Secondary outcomes compared between matched treatment groups

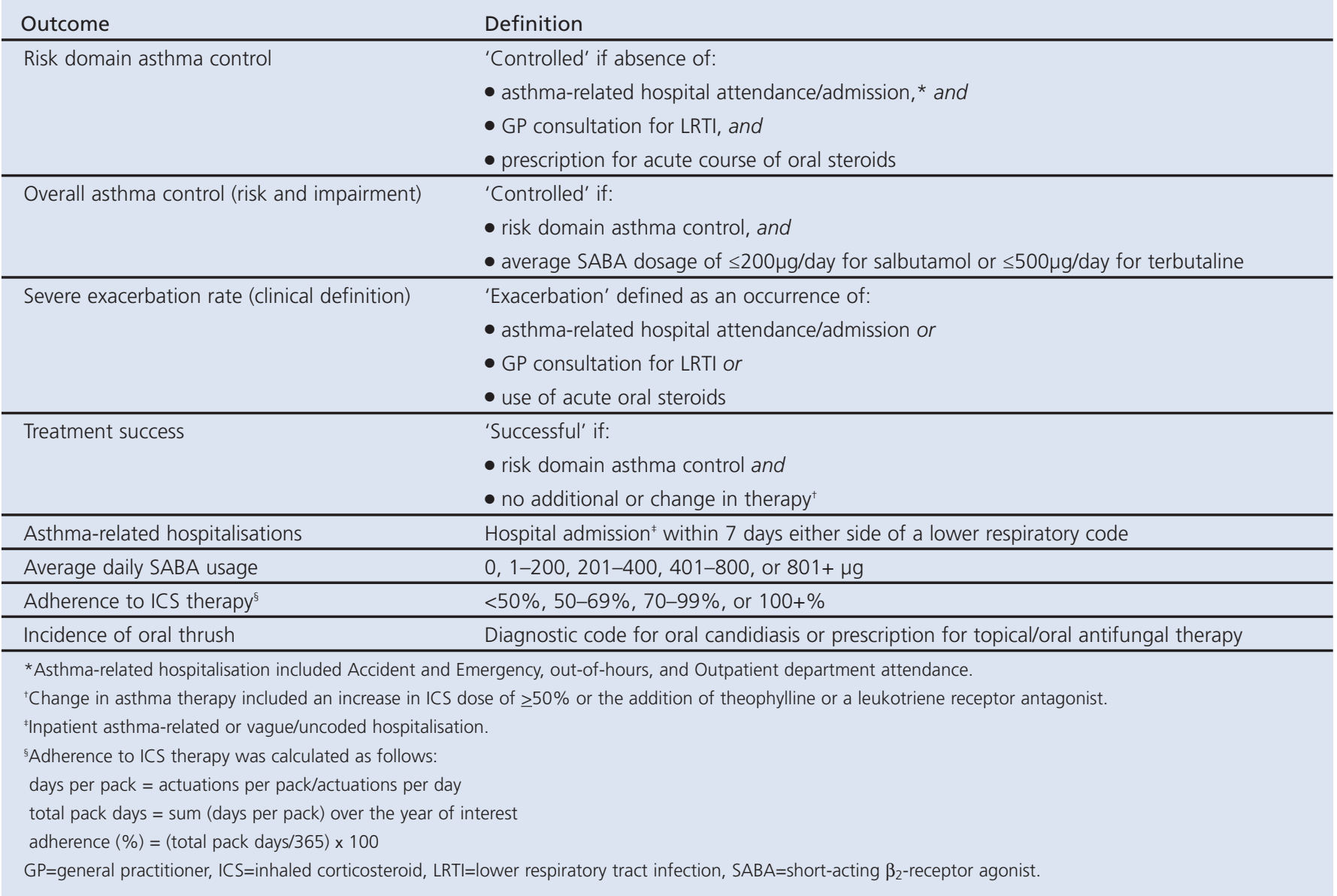

(outpatient, inpatient, and Accident and Emergency). Unit costs for GP consultations were derived from the Personal Social Services Research Unit report: Unit Costs of Health and Social Care 2011,38 assuming an average consultation duration of 11.7 minutes. Hospital usage costs were obtained from the NHS Reference Costs 2010-2011. ${ }^{39}$

\section{Statistical analyses}

All analyses were carried out using SPSS Statistics Version 20 (IBM, Armonk, New York, USA), SAS Version 9.3 (SAS Institute, Cary, North Carolina, USA), and Microsoft Excel 2007 (Microsoft, Redmond, Washington, USA). Statistically significant results were defined as $p<0.05$, and trends as $p \geq 0.05$ but $<0.10$. All adjusted odds/rate ratios and differences in proportions are presented with their 95\% confidence intervals (CI).

Exploratory data analysis was conducted for all variables of interest for the baseline and outcome years. Box 2 in the online Supplemental Materials lists all the potential confounders examined. Summary statistics for all baseline variables for the matched cohorts were compared using conditional logistic regression (for more information, see online Supplemental Materials).

\section{Clinical outcomes}

For the primary outcome, the total number of exacerbations in the outcome year was compared between treatment groups using a conditional Poisson regression model to obtain an estimate of relative exacerbation rates (further details are given in online Supplemental Materials).

To show 'at least equivalence' or non-inferiority in exacerbation prevention for efBDP-FOR compared with FP-SAL, the adjusted proportions of patients within each treatment group and the adjusted difference in proportions recording no exacerbations in the outcome year were calculated using a conditional binary logistic regression model. Non-inferiority was defined as the proportion of efBDP-FOR patients recording no exacerbations being no more than $10 \%$ lower than the proportion of patients remaining on FP-SAL recording no exacerbations. We chose a threshold of $-10 \%$ based on clinical experience and available literature. Although there is little agreement among statisticians, ${ }^{40,41}$ differences of $>10 \%$ are widely regarded as clinically important in related respiratory studies. ${ }^{41}$

For the secondary outcomes, adjusted odds and rates of events were compared between matched treatment groups using conditional binary/ordinal logistic regression or conditional Poisson regression models, respectively, as detailed in the online Supplemental Materials.

\section{Economic outcomes}

Generalised linear models with a logit link and gamma distribution were used to estimate mean asthma-related healthcare costs. Treatment costs were compared between groups via the differences in mean costs/patient/year, both unadjusted and adjusted for 
Table 3a. Clinically important baseline variables in matched treatment groups: variables used in patient matching (see Tables 3b and 3c in online Supplemental Materials for further baseline patient characterisation)

\begin{tabular}{|c|c|c|c|}
\hline Variable & $\begin{array}{l}\text { FP-SAL } \\
(n=1,146)\end{array}$ & $\begin{array}{l}\text { efBDP-FOR* } \\
(n=382)\end{array}$ & p Valuet \\
\hline \multicolumn{4}{|c|}{ Age at index prescription date (years) } \\
\hline $18-60$ & $723(63.1 \%)$ & $241(63.1 \%)$ & NA \\
\hline $61-80$ & $423(36.9 \%)$ & $141(36.9 \%)$ & \\
\hline Mean (SD) & $53.4(14.7)$ & $53.4(14.9)$ & 0.86 \\
\hline Median (IQR) & $53(43,65)$ & $54(43,65)$ & \\
\hline \multicolumn{4}{|l|}{ Gender } \\
\hline Male & $507(44.2 \%)$ & $169(44.2 \%)$ & NA \\
\hline Female & $639(55.8 \%)$ & $213(55.8 \%)$ & \\
\hline \multicolumn{4}{|l|}{ Smoking status } \\
\hline Non-smoker & $594(51.8 \%)$ & $198(51.8 \%)$ & NA \\
\hline Current smoker & $210(18.3 \%)$ & $70(18.3 \%)$ & \\
\hline Ex-smoker & $342(29.9 \%)$ & $114(29.9 \%)$ & \\
\hline \multicolumn{4}{|c|}{ Last prescribed ICS dosage (actual FP dosage, $\mu \mathrm{g} /$ day) } \\
\hline 200 & $99(8.6 \%)$ & $33(8.6 \%)$ & NA \\
\hline 250 & $33(2.9 \%)$ & $11(2.9 \%)$ & \\
\hline 500 & $816(71.2 \%)$ & $272(71.2 \%)$ & \\
\hline 1,000 & $198(17.3 \%)$ & $66(17.3 \%)$ & \\
\hline Mean (SD) & $553.3(223.6)$ & $553.3(223.7)$ & NA \\
\hline Median (IQR) & $500(500,500)$ & $500(500,500)$ & \\
\hline \multicolumn{4}{|c|}{ Type of consultation at index prescription date } \\
\hline Face-to-face & $321(28.0 \%)$ & $107(28.0 \%)$ & NA \\
\hline Electronic & $825(72.0 \%)$ & $275(72.0 \%)$ & \\
\hline \multicolumn{4}{|c|}{ Last prescribed ICS device } \\
\hline $\mathrm{MDI}$ & $1,059(92.4 \%)$ & $353(92.4 \%)$ & NA \\
\hline DPI & $87(7.6 \%)$ & $29(7.6 \%)$ & \\
\hline \multicolumn{4}{|c|}{ Courses of acute oral steroids } \\
\hline 0 & $936(81.7 \%)$ & $312(81.7 \%)$ & NA \\
\hline 1 & $141(12.3 \%)$ & $47(12.3 \%)$ & \\
\hline $2+$ & $69(6.0 \%)$ & $23(6.0 \%)$ & \\
\hline Mean (SD) & $0.29(0.76)$ & $0.34(1.13)$ & 0.081 \\
\hline Median (IQR) & $0(0,0)$ & $0(0,0)$ & \\
\hline \multicolumn{4}{|c|}{ SABA usage, average daily dose $(\mu \mathrm{g} /$ day $)$} \\
\hline 0 & $216(18.9 \%)$ & $72(18.9 \%)$ & NA \\
\hline $1-200$ & $336(29.3 \%)$ & $112(29.3 \%)$ & \\
\hline $201-400$ & $291(25.4 \%)$ & $97(25.4 \%)$ & \\
\hline $401-800$ & $240(20.9 \%)$ & $80(20.9 \%)$ & \\
\hline $801+$ & $63(5.5 \%)$ & $21(5.5 \%)$ & \\
\hline Mean (SD) & $279.7(289.2)$ & $296.4(348.2)$ & 0.022 \\
\hline Median (IQR) & $219(55,438)$ & $219(55,438)$ & \\
\hline \multicolumn{4}{|c|}{ Year of index prescription date } \\
\hline 2008 & $379(33.0 \%)$ & $26(6.8 \%)$ & $<0.001$ \\
\hline 2009 & $702(61.3 \%)$ & $178(46.6 \%)$ & \\
\hline 2010 & $63(5.5 \%)$ & $151(39.5 \%)$ & \\
\hline 2011 & $2(0.2 \%)$ & $27(7.1 \%)$ & \\
\hline \multicolumn{4}{|c|}{ Data are shown as $n(\%)$ unless otherwise indicated } \\
\hline \multicolumn{4}{|c|}{$\begin{array}{l}\text { *These patients were on FP-SAL during their baseline year but were switched } \\
\text { to efBDP-FOR at the index prescription date. }\end{array}$} \\
\hline \multicolumn{4}{|c|}{ †Conditional logistic regression. } \\
\hline \multicolumn{4}{|c|}{$\begin{array}{l}\text { DPI=dry powder inhaler, efBDP-FOR=extra-fine particle beclometasone and } \\
\text { formoterol as fixed-dose combination inhaler, FP=fluticasone propionate, } \\
\text { FP-SAL=fluticasone and salmeterol as fixed-dose combination inhaler, ICS=inhaled } \\
\text { corticosteroid, IQR=interquartile range, MDI=metered dose inhaler, NA=not } \\
\text { applicable (matching variable), SABA=short-acting } \beta_{2} \text {-receptor agonist, } \\
\text { SD=standard deviation. }\end{array}$} \\
\hline
\end{tabular}

potential confounders. Differences in adjusted mean costs are reported with $95 \% \mathrm{Cl}$ found by bootstrapping methods ${ }^{42}$ using 1,000 random samples taken, with replacement, from the dataset.

Cost effectiveness was determined using point estimates of differences in treatment cost and effectiveness between efBDP-FOR and FP-SAL using 1,000 replicated samples plotted to create a cost effectiveness plane, with FP-SAL as the reference treatment.

\section{Results}

\section{Baseline data}

Despite matching for most recent prescribed ICS dosage and several other clinically relevant variables, some significant baseline differences remained between treatment groups (Tables $3 a-c$ ). While the rates of rhinitis and cardiac disease were higher in the patients who would remain on FP-SAL, the patients who would be switched to efBDP-FOR appeared to have slightly more severe asthma, as evidenced by a higher rate of multiple asthma consultations, a greater number of respiratory prescriptions (particularly for ICS and SABA), and a higher average daily ICS dosage. The higher controller-to-reliever ratio in the patients who would be switched to efBDP-FOR suggests that these patients may have been more diligent in managing their asthma than those who would remain on FP-SAL. Regardless, there were no significant differences between treatment groups for any of the clinical outcome measures at baseline (see Table 3b in online Supplemental Materials).

\section{Daily ICS dosages at review/switch}

At the IPD, the majority of patients $(71.2 \%)$ were on a prescribed FP dosage of $500 \mu \mathrm{g} /$ day, $11.5 \%$ were on $200-250 \mu \mathrm{g} /$ day, and $17.3 \%$ were on 1,000 $\mu \mathrm{g} /$ day (Figure 2 ). These proportions did not change going into the outcome year in the patients remaining on FP-SAL. In the group switching to efBDP-FOR, 306 patients (80.1\%) were prescribed an efBDP dosage of $400 \mu \mathrm{g} /$ day and 76 patients $(19.9 \%$ ) a dosage of $200 \mu \mathrm{g} /$ day (Figure 2). These dosages were equivalent to the most recent FP-SAL prescription in 296 patients (77.5\%), and in the remaining 86 patients (22.5\%) they represented a reduction in ICS dosage of at least $50 \%$.

\section{Primary outcome}

There was no significant difference between treatment groups in the incidence of severe exacerbations during the outcome year (Table 4). The adjusted difference in proportions of patients recording no exacerbations was only $0.02(95 \% \mathrm{Cl}-0.03$ to 0.07$)$. As the threshold for non-inferiority was set at a difference of no more than $10 \%$ lower $(-0.10)$, efBDP-FOR was shown to be at least equivalent (non-inferior) to FP-SAL in this setting

\section{Secondary outcomes}

The efBDP-FOR patients were significantly more likely to achieve overall asthma control, have lower daily SABA usage, and be more adherent to ICS therapy than the FP-SAL patients (Table 5a; Figure 3). In addition, the average daily ICS dosage over the course of the outcome year was significantly lower in the efBDP-FOR group, by a mean of $130 \mu \mathrm{g} /$ day in FP-equivalent doses (Table 6).

There were no significant differences between treatment groups for risk domain asthma control, severe exacerbations (clinical definition), treatment success, inpatient asthma-related 
Figure 2. Actual ICS dosage prescribed at the Index Prescription Date in patients remaining on FP-SAL and those switched to efBDP-FOR (values for the efBDP-FOR group are actual BDP dosages, not FP-equivalents)

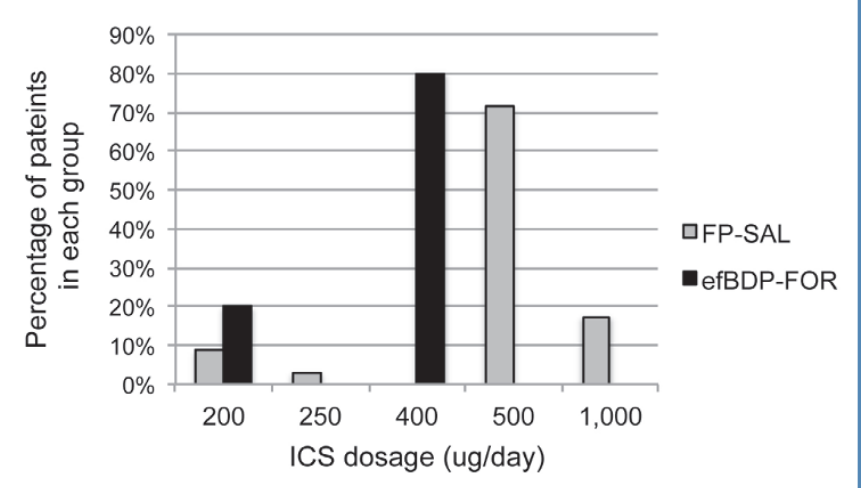

$\mathrm{BDP}=$ beclometasone dipropionate, efBDP-FOR=extra-fine particle beclometasone and formoterol as fixed-dose combination inhaler, $\mathrm{FP}=$ fluticasone propionate, $\mathrm{FP}-\mathrm{SAL}=$ fluticasone and salmeterol as fixed-dose combination inhaler, ICS=inhaled corticosteroid.

Table 4. Comparison of severe exacerbation rates

(ATS/ERS definition) between matched treatment groups during the outcome year

\begin{tabular}{lll}
\hline Severe exacerbations & $\begin{array}{l}\text { FP-SAL } \\
(\mathrm{n}=1,146)\end{array}$ & $\begin{array}{l}\text { efBDP-FOR } \\
(\mathrm{n}=382)\end{array}$ \\
\hline $0, \mathrm{n}(\%)$ & $918(80.1 \%)$ & $309(80.9 \%)$ \\
\hline $1, \mathrm{n}(\%)$ & $155(13.5 \%)$ & $49(12.8 \%)$ \\
\hline $2+, \mathrm{n}(\%)$ & $73(6.4 \%)$ & $24(6.3 \%)$ \\
\hline $\mathrm{p}=0.78$ & 1.01 \\
\hline Adjusted rate ratio* & 1.00 & 0.74 to 1.37 \\
\hline $95 \% \mathrm{Cl}$ & - & \\
\hline $\begin{array}{l}{ }^{*} \text { Adjusted for baseline confounders: numbers of SABA prescriptions and } \\
\text { asthma consultations. }\end{array}$ \\
$\begin{array}{l}\text { ATS/ERS=American Thoracic Society and European Respiratory Society, } \\
\text { Cl=confidence intervals, efBDP-FOR=extra-fine particle beclometasone and } \\
\text { formoterol as fixed-dose combination inhaler, FP-SAL=fluticasone and salmeterol } \\
\text { as fixed-dose combination inhaler, SABA=short-acting } \beta_{2} \text {-receptor agonist }\end{array}$
\end{tabular}

hospitalisations, or incidence of oral thrush during the outcome year (see Table $5 b$ in online Supplemental Materials). There were no significant interactions between treatment and smoking status for any outcomes.

\section{Health economic outcomes}

During the baseline year there were no significant differences between treatment groups for asthma-related total healthcare or drug costs. However, there was a trend $(p=0.061)$ for higher healthcare costs in the patients who would be switched to efBDP$F O R$, driven by significantly higher costs for their FDC inhalers $(p=0.016)$ and asthma consultations $(p<0.001)$.

During the outcome year asthma-related total healthcare and drug costs were both significantly lower in patients switched to efBDP-FOR than in those remaining on FP-SAL $(p<0.001$ for both
Table 5a. Comparison of secondary outcomes between matched treatment groups during the outcome year (for the full version of this table, see Table $5 b$ in online

\section{Supplemental Materials)}

\begin{tabular}{|c|c|c|}
\hline Outcome & $\begin{array}{l}\text { FP-SAL } \\
(n=1,146)\end{array}$ & $\begin{array}{l}\text { efBDP-FOR } \\
(\mathrm{n}=382)\end{array}$ \\
\hline \multicolumn{3}{|c|}{ Overall asthma control (risk and impairment) } \\
\hline Adjusted odds ratio* & 1.00 & 1.56 \\
\hline$(95 \% \mathrm{Cl})$ & & (1.14 to 2.14$)$ \\
\hline \multicolumn{3}{|c|}{ Average daily SABA usage } \\
\hline Adjusted odds ratio* & 1.00 & 0.74 \\
\hline$(95 \% \mathrm{Cl})$ & & (0.60 to 0.91$)$ \\
\hline \multicolumn{3}{|c|}{ Adherence to ICS therapy } \\
\hline Odds ratio & 1.00 & 1.40 \\
\hline$(95 \% \mathrm{Cl})$ & & $(1.13$ to 1.73$)$ \\
\hline
\end{tabular}

*Adjusted for baseline confounders (see Table 5b in online Supplemental Materials) $\mathrm{Cl}=$ confidence intervals, efBDP-FOR=extra-fine particle beclometasone and formoterol as fixed-dose combination inhaler, FP-SAL=fluticasone and salmeterol as fixed-dose combination inhaler, ICS=inhaled corticosteroid, SABA=short-acting $\beta_{2}$-receptor agonist.

Figure 3. Adherence to ICS therapy in matched treatment groups during their baseline and outcome years (patients in the 'efBDP-FOR baseline' group were on FP-SAL during their baseline year but were switched to efBDP-FOR at the index prescription date.)

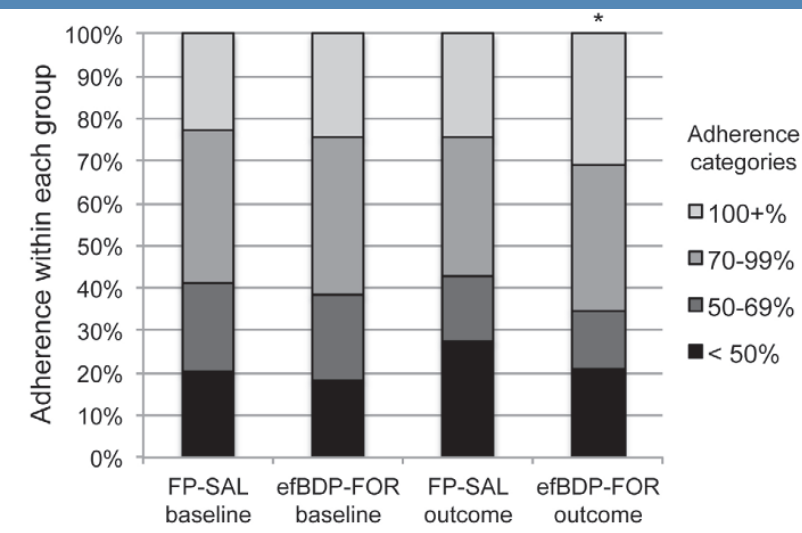

Adherence was categorised as <50\%, 50-69\%, 70-99\%, and 100+\% compliance with the prescribed ICS dosage. *Adherence to ICS therapy was significantly greater in the efBDP-FOR patients than in the FP-SAL patients during the outcome year $(p=0.001)$. efBDP-FOR=extra-fine particle beclometasone and formoterol as fixed-dose combination inhaler, FP$\mathrm{SAL}=$ fluticasone and salmeterol as fixed-dose combination inhaler, ICS=inhaled corticosteroid

indices). Adjusted for baseline costs, the mean asthma-related total healthcare costs for the outcome year were $f 438.82$ /patient (95\% $\mathrm{Cl} £ 421.94$ to $£ 456.25)$ for the FP-SAL group and $£ 345.19 /$ patient ( $95 \% \mathrm{Cl} £ 327.96$ to $f 362.90$ ) for the efBDP-FOR group, a difference of $f 93.63 /$ patient/year ( $95 \% \mathrm{Cl} f 73.65$ to $f 114.27$ ), or f7.89/patient/month.

The single greatest contributor to the total healthcare cost was 


\begin{tabular}{|c|c|c|}
\hline & $\begin{array}{l}\text { FP-SAL } \\
(n=1,146)\end{array}$ & $\begin{array}{l}\text { efBDP-FOR } \\
(n=382)\end{array}$ \\
\hline \multicolumn{3}{|c|}{ Average daily ICS dose, $\mathrm{n}(\%)$} \\
\hline $1-200 \mu \mathrm{g}$ & $203(17.7 \%)$ & $92(24.1 \%)$ \\
\hline $201-400 \mu \mathrm{g}$ & $350(30.6 \%)$ & $197(51.5 \%)$ \\
\hline $401-600 \mu \mathrm{g}$ & $352(30.7 \%)$ & $74(19.4 \%)$ \\
\hline $601+\mu \mathrm{g}$ & $241(21.0 \%)$ & $19(5.0 \%)$ \\
\hline Mean (SD), $\mu \mathrm{g} /$ day & $455.0(304.8)$ & $324.5(159.3)$ \\
\hline Median (IQR) $\mu \mathrm{g} /$ day & $411.0(246.6,575.4)$ & $295.9(230.2,394.5)$ \\
\hline p Value* & $<0.001$ & \\
\hline \multicolumn{3}{|c|}{$\begin{array}{l}\text { *Conditional logistic regression. } \\
\text { efBDP-FOR=extra-fine particle beclometasone and formoterol as fixed-dose } \\
\text { combination inhaler, FP=fluticasone propionate, FP-SAL=fluticasone and } \\
\text { salmeterol as fixed-dose combination inhaler, ICS=inhaled corticosteroid, } \\
\text { IQR=interquartile range, SD=standard deviation. }\end{array}$} \\
\hline
\end{tabular}

the cost of FDC inhaler therapy, so these differences were driven by the significantly lower cost of FDC inhaler therapy in the efBDP-FOR group $(p<0.001)$. All other costs (drugs, consultations, hospitalisations) were comparable between treatment groups. The mean cost of FDC inhaler therapy for the outcome year was

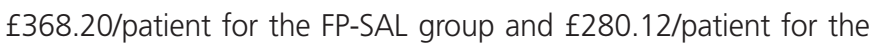
efBDP-FOR group, a difference of $£ 88.08 /$ patient/year, or f7.34/patient/month.

Based on point estimates of differences in cost and effectiveness using 1,000 replicated samples, efBDP-FOR was both less costly and more effective than FP-SAL in this setting. Using exacerbation prevention (ATS/ERS definition) as the measure of treatment effectiveness, there was a $75 \%$ probability that efBDP-FOR is less costly and more effective than FP-SAL (Figure 4). Using risk domain asthma control as the measure of effectiveness, there was an $87 \%$ probability that efBDP-FOR is less costly and more effective in this setting.

\section{Discussion}

\section{Main findings}

In this heterogeneous population of patients requiring ICS-LABA therapy for asthma control, efBDP-FOR was at least as effective as FP$\mathrm{SAL}$ in preventing severe exacerbations. In addition, switching from FP-SAL to efBDP-FOR at an equivalent or lower daily ICS dosage resulted in improved odds of achieving overall asthma control, lower daily SABA usage, and better adherence to ICS therapy, all at a lower daily ICS dosage. Furthermore, switching from FP-SAL to efBDP-FOR was cost-effective, efBDP-FOR being more effective and less costly than FP-SAL in this patient population.

\section{Strengths and limitations of this study}

There are three main strengths of our study: (1) its large and diverse patient population, with few clinically relevant exclusion criteria; (2) its relatively long duration; and (3) its non-interventional nature. By including patients with significant co-morbidities, smokers, and patients with poor adherence to their ICS prescription, most of the challenges typically faced in primary asthma care were represented
Figure 4. Cost-effectiveness of switching from FP-SAL to efBDP-FOR, with treatment effectiveness based on

exacerbation prevention (ATS/ERS definition) during the outcome year. Costs are total asthma-related healthcare costs ( $f /$ patient/year), adjusted for baseline differences

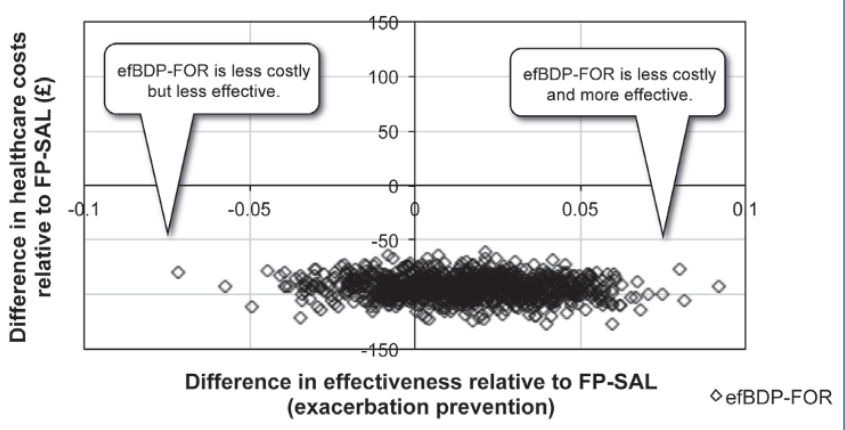

ATS/ERS=American Thoracic Society and European Respiratory Society, efBDP-FOR=extra-fine particle beclometasone and formoterol as fixed-dose combination inhaler, FP-SAL=fluticasone and salmeterol as fixed-dose combination inhaler

in our study population. In addition, our study examined 12 months of patient data both before and after the index patient review/switch, so the effects of seasonal or other transient confounders - including a change in therapy - were minimised. Furthermore, the retrospective nature of data acquisition meant that our study protocol did not affect patient behaviour in any way, particularly with respect to inhaler use and physician contact.

In contrast, the RCTs which compared efBDP-FOR with FP-SAL ${ }^{15}$ and BUD-FOR ${ }^{26}$ followed only 114 and 109/110 carefully selected patients, respectively, and for a treatment period of only 12 weeks. Furthermore, those study protocols required frequent clinic visits over the course of the investigation period, ${ }^{15,26}$ which likely influenced treatment adherence and thus outcomes. ${ }^{43,44}$ Our study showed that efBDP-FOR is comparable to FP-SAL - and in some measures superior - in real-life asthma patients.

The main limitations of our study are those inherent to retrospective studies, and to observational studies of any kind. ${ }^{43,44}$ There are trade-offs in the scope and thus the findings of any study. Specifically, our study design precluded a thorough evaluation of adverse effects with either ICS-LABA combination in this patient population. In order to achieve our objectives, it was necessary to include only those patients with complete data for both baseline and outcome years. Our study design thus precluded an evaluation of asthma-related deaths and other rare significant adverse effects with either FDC inhaler.

Another limitation of our study was the need to rely on anonymised medical records for the diagnosis of asthma and the exclusion of other chronic respiratory disorders such as chronic obstructive pulmonary disease (COPD). Using diagnostic spirometry, it has been estimated that about $25 \%$ of asthma patients over the age of 40 may have COPD. ${ }^{45}$ Given the age distribution and smoking status of the patients in our study, we estimate that a maximum of $10 \%$ of the patients may have had COPD instead of - or in addition 
to - asthma. As age and smoking status were matching variables, any such patients would have been fairly equally distributed among the two treatment groups.

\section{Interpretation of findings in relation to previously published work}

The clinical effectiveness of efBDP-FOR in asthma patients requiring combination ICS-LABA therapy is well established. . $216,21-27,46,47$ However, to our knowledge, no studies have evaluated both the clinical and cost effectiveness of switching from another ICS-LABA combination to efBDP-FOR in the typical asthma patient - a scenario that is likely to be increasingly common in primary care, given the substantially lower cost and comparable effectiveness of the efBDP-FOR inhaler and, in the UK, certain NHS recommendations to physicians. ${ }^{2}$

The effectiveness of stepping down from high-dose FP-SAL to moderate-dose FP-SAL (step-down) or efBDP-FOR (step-down plus switch) was recently shown in a prospective RCT. The study concluded that efBDP-FOR $(400 \mu \mathrm{g} /$ day efBDP) was equivalent to moderate-dose FP-SAL $(500 \mu \mathrm{g} /$ day FP) in morning pre-dose peak expiratory flow, and asthma control was maintained in $96 \%$ of the patients following treatment step-down (from 1,000 $\mathrm{g} /$ day FP). ${ }^{14} \mathrm{In}$ another recent RCT, asthma patients previously controlled with FPSAL (500 $\mu \mathrm{g} /$ day FP) were effectively stepped across or switched to efBDP-FOR $(400 \mu \mathrm{g} /$ day efBDP); lung function and asthma control were maintained, no safety issues were reported, and efBDP-FOR was noted to have a relatively rapid $(5 \mathrm{~min})$ onset of action. ${ }^{25}$ However, those studies involved carefully selected patient populations, as is typical of a RCT, and did not include cost analyses.

An Italian study ${ }^{48}$ conducted a post hoc cost-effectiveness and cost-utility analysis of the data from the RCT on which the noninferiority of efBDP-FOR to FP-SAL was based. ${ }^{15}$ From the perspective of the Italian NHS, efBDP-FOR was more cost effective than FP-SAL and offered a slight advantage over FP-SAL in weeks spent successfully controlled and in quality-adjusted life years. ${ }^{48}$ However, that study involved only 114 carefully selected patients in each treatment group and followed the patients for only 12 weeks of treatment. ${ }^{15}$ None of these RCTs examined a broad population of asthma patients.

The PRISMA (PRospectlve Study on asthMA control) study group followed 1,017 real-life asthma patients for 12 months, including smokers, ex-smokers, and patients with co-morbidities. ${ }^{24,27}$ Of the 739 patients evaluable after 12 months, 569 patients were treated using an ICS-LABA combination. The patients on efBDP-FOR had significantly better asthma control and quality of life compared with patients on FP-SAL or BUD-FOR. ${ }^{24}$ In another study of real-life asthma patients, treatment with efBDP-FOR led to significant improvements in pulmonary function and asthma control, regardless of the patient's smoking status, and the medication was well tolerated. ${ }^{47}$ However, while these studies indicate that efBDP-FOR is both safe and effective for asthma control in typical asthma patients, a study of real-life asthma patients switching from FP-SAL to efBDP-FOR was necessary in order to confirm that switching is both clinically and cost effective in this broad patient population.

Implications for future research, policy and practice

One direction for future research is the outcome, in clinical and cost effectiveness, of stepping down the ICS dosage in typical asthma patients switching to efBDP-FOR from another ICS-LABA combination. The British Thoracic Society and Scottish Intercollegiate Guidelines Network recommend stepping down ICS therapy once asthma is controlled, advising a treatment review every three months and a decrease in dosage by approximately $25-50 \%$ each time if appropriate..$^{49}$ Only 86 patients in our study were switched to efBDPFOR at an ICS dosage that was substantially lower than their last FPSAL prescription, so meaningful statistical analysis was not possible.

Another avenue worth exploring is the use of efBDP-FOR as single inhaler MART. A recent RCT found that efBDP-FOR used both for daily maintenance and as-needed reliever therapy was well tolerated and superior to a combination of daily maintenance with efBDP-FOR and as-needed SABA (salbutamol). The MART approach with efBDP-FOR significantly increased the time to first severe exacerbation (ATS/ERS definition) by 75 days, reduced the risk of exacerbation by $36 \%$, and resulted in fewer courses of oral steroids and asthma-related hospitalisations compared with the efBDP-FOR + SABA combination. ${ }^{22}$ It would be interesting to evaluate the cost effectiveness of this approach, as it is possible that even further asthma-related cost savings could be realised without a significant reduction in clinical effectiveness or an increase in risk.

\section{Conclusions}

Switching asthma patients from FP-SAL to efBDP-FOR at an equivalent or lower ICS dosage is both less costly and more effective.

\section{Handling editor Anthony D'Urzo \\ Statistical review Gopal Netuveli}

Acknowledgements We thank Stan D Musgrave, Julie von Ziegenweidt, Francesca Barion, and Anna Rigazio for help with the statistical and data analyses. Conflicts of interest DP has consultant arrangements with Almirall, AstraZeneca (AZ), Boehringer Ingelheim, Chiesi, GlaxoSmithKline (GSK), Merck, Mundipharma, Medapharma, Novartis, Napp, Nycomed, Pfizer, Sandoz, and Teva. He or his research team have received grants and support for research in respiratory disease from the following organisations in the last 5 years: UK National Health Service, Aerocrine, AZ, Boehringer Ingelheim, Chiesi, GSK, Merck, Mundipharma, Novartis, Nycomed, Orion, Pfizer and Teva. He has spoken for Almirall, AZ, Activaero, Boehringer Ingelheim, Chiesi, Cipla, GSK, Kyorin, Novartis, Merck, Mundipharma, Pfizer, and Teva. He has shares in AKL Ltd which produces phytopharmaceuticals. He is the sole owner of Research in Real Life Ltd and its subsidiary social enterprise Optimum Patient Care. IS has received honoraria and support to attend international conferences from Almirall, $A Z$, Boehringer Ingelheim, Chiesi, GSK, NAPP, Novartis, and Orion. He is an Associate editor of the $P C R J$, but was not involved in the editorial review of, nor the decision to publish, this article. JH has provided occasional consultancy or speaker services for Almirall, AZ, Boehringer Ingelheim, Chiesi, GSK, Merck, Novartis, Sharpe and Dohme, and Teva. DR has lectured on behalf of, received sponsorship from, or provided consultancy services to: AZ, GSK, MSD, Schering Plough, Uriach Pharma, Chiesi, NAPP, Meda Pharmaceuticals, Nycomed, BI, Pfizer, and Novartis Pharma. KG-J has acted as a consultant for and spoken on behalf of GSK, AZ, Chiesi, Boehringer Ingelheim, MSD, Mundi Pharma/Napp, Almirall, Novartis, and Sandoz. FL has been reimbursed for attending conferences and/or giving talks by Chiesi, Farmaceutici, Menarini Industrie Farmaceutiche, Mundipharma, AZ, and Pfizer. TH is an employee of Chiesi UK Ltd. AB and JB are employees of Research in Real Life. CK declares that she has no conflicts of interest in relation to this article. AP (or members of his research team) has received grants for research in respiratory disease and he has received honoraria for participation in scientific meetings and advisory boards from AZ, Boehringer Ingelheim, Chiesi, GSK, MSD, Mundipharma, Novartis, Nycomed, Pfizer, and Zambon.

Contributorship DP, IS, JH, DR, KG-J, FL, and AP conceived and designed the study; $A B$ and JB conducted the statistical and data analyses respectively; and $C K$ 
prepared the manuscript. All authors contributed to the interpretation of the data, writing of the manuscript, and review of the final draft. The study guarantor is DP. Funding The study was sponsored by Chiesi UK Ltd. The funders had no role in the conduct of the study, interpretation of study results, or preparation of the manuscript.

\section{References}

1. Office for National Statistics. 2011 Census - Population and household estimates for England and Wales, March 2011 (report on the internet). Newport: Office for National Statistics, 16 July 2012 (updated 20 July 2012). Available from http://www.ons.gov.uk/ons/dcp171778_270487.pdf (accessed 4 May 2013).

2. Homan K. Briefing paper: Primary care switch protocol - low and moderate dose ICS/LABA combination inhalers switch to Fostair 100/6 inhaler (bulletin on the internet). Cambridge: NHS East of England, June 2011. Available from http://www.see.nhs.uk/content/file/GP\%20Zone/Medicine\%20management/QOF/ nhalers/129-bulletin-5.pdf (accessed 4 May 2013).

3. Summary of product characteristics, Fostair 100/6 (article on the internet). Cheadle: Chiesi Ltd, 19 December 2012. Available from http://www.chiesi.uk.com/system/ file2s/23/original/Fostair_CSP017-5_.pdf?1357136993 (accessed 11 May 2013)

4. Leach CL, Davidson PJ, Boudreau RJ. Improved airway targeting with the CFC-free HFA-beclomethasone metered-dose inhaler compared with CFC-beclomethasone. Eur Respir J 1998;12(6):1346-53. http://dx.doi.org/10.1183/09031936.98.12061346

5. Goldin JG, Tashkin DP, Kleerup EC, et al. Comparative effects of hydrofluoroalkane and chlorofluorocarbon beclomethasone dipropionate inhalation on small airways: assessment with functional helical thin-section computed tomography. J Allergy Clin Immunol 1999; 104(6):S258-67.

6. Leach CL, Davidson PJ, Hasselquist BE, Boudreau RJ. Lung deposition of hydrofluoroalkane-134a beclomethasone is greater than that of chlorofluorocarbon fluticasone and chlorofluorocarbon beclomethasone: a cross-over study in healthy volunteers. Chest 2002;122(2):510-16. http://dx.doi.org/10.1378/chest.122.2.510

7. Leach $\mathrm{CL}$, Davidson PJ, Hasselquist BE, Boudreau RJ. Influence of particle size and patient dosing technique on lung deposition of HFA-beclomethasone from a metered dose inhaler. J Aerosol Med 2005; 18(4):379-85 http://dx.doi.org/10.1089/jam.2005.18.379

8. Thongngarm T, Silkoff PE, Kossack WS, Nelson HS. Hydrofluoroalkane-134A beclomethasone or chlorofluorocarbon fluticasone: effect on small airways in poorly controlled asthma. J Asthma 2005;42(4):257-63. http://dx.doi.org/10.1081/JAS-200057888

9. Verbanck S, Schuermans D, Paiva M, Vincken W. The functional benefit of antiinflammatory aerosols in the lung periphery. I Allergy Clin Immunol 2006; 118(2):340-6. http://dx.doi.org/10.1016/j.jaci.2006.04.056

10. Yamaguchi $M$, Niimi $A$, Ueda $T$, et al. Effect of inhaled corticosteroids on small airways in asthma: investigation using impulse oscillometry. Pulm Pharmacol Ther 2009;22(4):326-32. http://dx.doi.org/10.1016/j.pupt.2009.01.005

11. De Backer W, Devolder A, Poli G, et al. Lung deposition of BDP/formoterol HFA pMDI in healthy volunteers, asthmatic, and COPD patients. J Aerosol Med Pulm Drug Deliv 2010;23(3):137-48. http://dx.doi.org/10.1089/jamp.2009.0772

12. Scichilone N, Battaglia S, Sorino C, et al. Effects of extra-fine inhaled beclomethasone/formoterol on both large and small airways in asthma. Allergy 2010;65(7):897-902. http://dx.doi.org/10.1111/j.1398-9995.2009.02306.x

13. Corda L, Gardenghi GG, Modina D, Montemurro LT, Novali M, Tantucci C. Effects on small airway obstruction of long-term treatments with beclomethasone/formoterol hydrofluoroalkane (metered-dose inhaler) versus fluticasone/salmeterol (dry-powder inhaler) in asthma: a preliminary study. Allergy Asthma Proc 2011;32(6):29-34. http://dx.doi.org/10.2500/aap.2011.32.3477

14. Papi A, Nicolini G, Crimi N, et al. Step-down from high dose fixed combination therapy in asthma patients: a randomized controlled trial. Respir Res 2012;13:54. http://dx.doi.org/10.1186/1465-9921-13-54

15. Papi A, Paggiaro P, Nicolini G, Vignola AM, Fabbri LM; ICAT SE Study Group. Beclomethasone/formoterol vs. fluticasone/salmeterol inhaled combination in moderate to severe asthma. Allergy 2007;62(10):1182-8.

16. Müller $V$, Gálffy $G$, Eszes $N$, et al. Asthma control in patients receiving inhaled corticosteroid and long-acting beta2-agonist fixed combinations. A real-life study comparing dry powder inhalers and a pressurized metered dose inhaler extrafine formulation. BMC Pulm Med 2011;11:40. http://dx.doi.org/10.1186/1471-2466-11-40.
17. Laube BL, Janssens HM, de Jongh FH, et al. What the pulmonary specialist should know about the new inhalation therapies. Eur Respir J 2011;37(6):1308-31. http://dx.doi.org/10.1183/09031936.00166410

18. Palmqvist M, Persson G, Lazer L, Rosenborg J, Larsson P, Lötvall J. Inhaled dry-powder formoterol and salmeterol in asthmatic patients: onset of action, duration of effect and potency. Eur Respir J 1997;10(11):2484-9. http://dx.doi.org/10.1183/09031936.97.10112489

19. Politiek MJ, Boorsma M, Aalbers R. Comparison of formoterol, salbutamol and salmeterol in methacholine-induced severe bronchoconstriction. Eur Respir $J$ 1999;13(5):988-92. http://dx.doi.org/10.1034/j.1399-3003.1999.13e10.x

20. van Noord JA, Smeets JJ, Maesen FP. A comparison of the onset of action of salbutamol and formoterol in reversing methacholine-induced bronchoconstriction. Respir Med 1998;92(12):1346-51. http://dx.doi.org/10.1016/50954-6111(98)90140-8

21. Singh $D$, Corradi $M$, Bindi $E$, Baronio R, Petruzzelli S, Paggiaro P. Relief of methacholine-induced bronchospasm with extrafine beclomethasone dipropionate/formoterol in comparison with salbutamol in asthma. Pulm Pharmacol Ther 2012;25(5):392-8. http://dx.doi.org/10.1016/.pupt.2012.07.004

22. Papi A, Corradi M, Pigeon-Francisco $\mathrm{C}$ et al. Beclometasone-formoterol as maintenance and reliever treatment in patients with asthma: a double-blind, randomised controlled trial. Lancet Respir Med 2013;1(1):23-31. http://dx.doi.org/10.1016/\$2213-2600(13)70012-2

23. Huchon G, Magnussen H, Chuchalin A, Dymek L, Gonod FB, Bousquet J. Lung function and asthma control with beclomethasone and formoterol in a single inhaler. Respir Med 2009;103(1):41-9. http://dx.doi.org/10.1016/j.rmed.2008.09.002

24. Terzano C, Cremonesi G, Girbino G, et al. 1-year prospective real life monitoring of asthma control and quality of life in Italy. Respir Res 2012;13:112. http://dx.doi.org/10.1186/1465-9921-13-112

25. Barnes N, van Noord JA, Brindicci C, et al. Stepping-across controlled asthmatic patients to extrafine beclometasone/formoterol combination. Pulm Pharmacol Ther 2013;26(5):555-61. http://dx.doi.org/10.1016/j.pupt.2013.01.011

26. Papi A, Paggiaro PL, Nicolini G, Vignola AM, Fabbri LM; ICAT SY Study Group. Beclomethasone/formoterol versus budesonide/formoterol combination therapy in asthma. Eur Respir J 2007;29(4):682-9 (errata in Eur Respir J 2007;29(6):1286 and 2008;32(3):822)

27. Allegra L, Gremonesi G, Girbino $G$, et al. Real-life prospective study on asthma control in Italy: cross-sectional phase results. Respir Med 2012;106(2):205-14. http://dx.doi.org/10.1016/jrmed.2011.10.001

28. Busse WW, Brazinsky $S$, Jacobson $K$, et al. Efficacy response of inhaled beclomethasone dipropionate in asthma is proportional to dose and is improved by formulation with a new propellant. J Allergy Clin Immunol 1999;104(6):1215-22. http://dx.doi.org/10.1016/S0091-6749(99)70016-3

29. Rigamonti E, Kottakis I, Pelc M, Grzelewska Rzymowska I, Feschenko Y. Comparison of a new extrafine beclomethasone dipropionate HFA 134a-formulated pMDI with a standard BDP CFC pMDI in adults with moderate persistent asthma. Eur Respir J 2006;28(Suppl 50):S1236.

30. Barnes N, Price D, Colice $G$, et al. Asthma control with extrafine-particle hydrofluoroalkane-beclometasone vs. large-particle chlorofluorocarbonbeclometasone: a real-world observational study. Clin Exp Allergy 2011;41:152132. http://dx.doi.org/10.1111/j.1365-2222.2011.03820.x

31. Price $\mathrm{D}, \mathrm{Martin} \mathrm{RJ}$, Barnes $\mathrm{N}$, et al. Prescribing practices and asthma control with hydrofluoroalkane-beclomethasone and fluticasone: a real-world observational study. J Allergy Clin Immunol 2010;126(3):511-18. http://dx.doi.org/10.1016/j.jaci.2010.06.040

32. Shepherd J, Rogers G, Anderson R, et al. Systematic review and economic analysis of the comparative effectiveness of different inhaled corticosteroids and their usage with long-acting beta2 agonists for the treatment of chronic asthma in adults and children aged 12 years and over. Health Technol Assess 2008;12(19):iii-xiv, 1-360. Available from http://www.hta.ac.uk/fullmono/mon1219.pdf (accessed 28 May 2013).

33. Fanta CH. Asthma. N Engl J Med 2009;360(10):1002-14. http://dx.doi.org/ 10.1056/NEJMra0804579 (errata in N Engl J Med 2009;360(16):1685 and 361(11):1123). http://dx.doi.org/10.1056/NEJMra0804579

34. Tamm M, Richards DH, Beghé B, Fabbri L. Inhaled corticosteroid and long-acting B2agonist pharmacological profiles: effective asthma therapy in practice. Respir Med 2012;106(S1):S9-19. http://dx.doi.org/10.1016/S0954-6111(12)70005-7 
35. Colice G, Martin RJ, Israel E, et al. Asthma outcomes and costs of therapy with extrafine beclomethasone and fluticasone. J Allergy Clin Immunol 2013;132(1):4554. http://dx.doi.org/10.1016/j.jaci.2013.02.008

36. Price $D$, Bousquet J. Real-world perceptions of inhaled corticosteroid/long-acting $\beta 2$ agonist combinations in the treatment of asthma. Respir Med 2012;106(S1):S4-8. http://dx.doi.org/10.1016/S0954-6111(12)70004-5

37. Reddel HK, Taylor DR, Bateman ED, et al. An official American Thoracic Society/European Respiratory Society statement: Asthma control and exacerbations; standardized endpoints for clinical asthma trials and clinical practice. Am J Respir Crit Care Med 2009;180(1):59-99. http://dx.doi.org/10.1164/rccm.200801-060ST

38. Curtis L. Unit Costs of Health and Social Care 2011. Personal Social Services Research Unit, The University of Kent, Canterbury, UK, 2011. Available at http://www.pssru.ac.uk/pdf/uc/uc2011/uc2011.pdf (accessed September 2012).

39. Department of Health. NHS reference costs 2010-2011. Published 17 November 2011. Available at: https://www.gov.uk/government/publications/2010-11reference-costs-publication (accessed September 2012).

40. Huitfeldt B, Hummel J. The draft FDA guideline on non-inferiority clinical trials: a critical review from European pharmaceutical industry statisticians. Pharm Stat 2011;10(5):414-19. http://dx.doi.org/10.1002/pst.508

41. Chapman KR, Bergeron C, Bhutani M, Bourbeau J, Grossman RF, Hernandez P, et al. Do we know the minimal clinically important difference (MCID) for COPD exacerbations? COPD 2013;10(2):243-9. http://dx.doi.org/10.3109/15412555.2012.733463

42. Briggs $A H$, Wonderling DE, Mooney $C Z$. Pulling cost-effectiveness analysis up by its bootstraps: a non parametric approach to confidence interval estimation. Health Econ 1997;6(4):327-40. http://dx.doi.org/10.1002/(SICI)1099-1050(199707)6: 4<327::AID-HEC282>3.0.CO;2-W
43. Price D, Bjermer L, Haughney J, et al. Real-life asthma strategies: the missing piece in the jigsaw (article on the internet). Treatment Strategies-Respiratory 2013;3(2):37-46. Available from http://www.effectivenessevaluation.org/wpcontent/uploads/2013/03/Real-life-Asthma-Strategies-The-Missing-Piece-in-theJigsaw_13Feb13.pdf (accessed 16 May 2013).

44. Price D, Hillyer EV, van der Molen T. Efficacy versus effectiveness trials: informing guidelines for asthma management. Curr Opin Allergy Clin Immunol 2013;13(1):50-7. http://dx.doi.org/10.1097/ACI.0b013e32835ad059

45. Tinkelman DG, Price DB, Nordyke RJ, Halbert RJ. Misdiagnosis of COPD and asthma in primary care patients 40 years of age and over. J Asthma 2006;43(1):75-80. http://dx.doi.org/10.1080/02770900500448738

46. Singh D, Piccinno A, Borrill Z, et al. Tolerability of high cumulative doses of the HFA modulite beclomethasone dipropionate/formoterol combination inhaler in asthmatic patients. Pulm Pharmacol Ther 2008;21(3):551-7. http://dx.doi.org/10.1016/j.pupt.2008.01.001

47. Brusselle G, Peché R, Van den Brande P, Verhulst A, Hollanders W, Bruhwyler J. Reallife effectiveness of extrafine beclometasone dipropionate/formoterol in adults with persistent asthma according to smoking status. Respir Med 2012;106(6):811-19. http://dx.doi.org/10.1016/j.rmed.2012.01.010

48. Gerzeli S, Rognoni C, Quaglini S, Cavallo MC, Cremonesi G, Papi A. Costeffectiveness and cost-utility of beclomethasone/formoterol versus fluticasone propionate/salmeterol in patients with moderate to severe asthma. Clin Drug Investig 2012;32(4):253-65. http://dx.doi.org/10.2165/11598940

49. Healthcare Improvement Scotland. British Guideline on the Management of Asthma (booklet on the internet). London/Edinburgh: British Thoracic Society and Scottish Intercollegiate Guidelines Network. May 2008 (revised January 2012). Available from http://www.sign.ac.uk/pdf/sign101.pdf (accessed 17 May 2013).

Available online at http://www.thepcrj.org 


\section{Materials and methods}

The FP-SAL inhalers under investigation were the Seretide ${ }^{\circledR}$ Accuhaler and the Seretide ${ }^{\circledast}$ Evohaler (Allen \& Hanburys Ltd, Uxbridge, Middlesex, UK). Each single dose of the Accuhaler contains 100,250 , or $500 \mu \mathrm{g}$ of fluticasone propionate and $50 \mu \mathrm{g}$ of salmeterol xinafoate. Each single actuation of the Evohaler contains 50,125 , or $250 \mu \mathrm{g}$ of fluticasone propionate and $25 \mu \mathrm{g}$ of salmeterol xinafoate. The efBDP-FOR inhaler was Fostair ${ }^{\circledR}$ 100/6 (Chiesi Ltd, Highfield, Cheadle, UK). Each metered dose contains 100 $\mathrm{ug}$ of extra-fine particle beclometasone dipropionate and $6 \mu \mathrm{g}$ of formoterol fumarate dihydrate. The Fostair inhaler uses Modulite technology, so it generates a slower plume of aerosolised medication than earlier formulations, which may help with pulmonary deposition. ${ }^{1}$

\section{Study design}

The baseline year of data collection was used for patient matching, to identify and characterise any confounders, and to allow for seasonal changes in respiratory disease and its related conditions. It also established that the patients were relatively well controlled on FP-SAL at their current dosage, as at the index review the physician saw no need to increase the ICS dosage. This aspect of the study design was important in comparing the two FDC inhalers on equal footing while examining the results of the switch.

Figure S1 summarises the patient selection process prior to case matching. The databases identified 1,113,776 patients who were being treated with ICS therapy. Patients were considered for inclusion if they received a prescription for either FP-SAL or efBDPFOR as single FDC inhaler therapy after 1 January 2008 and received no other ICS or LABA prescriptions on the same date. On this basis, 930,645 patients were excluded.

Patients further considered for inclusion had a recorded diagnostic code for asthma; no recorded diagnosis for chronic obstructive pulmonary disease or other chronic respiratory disease; at least two prescriptions for FP-SAL as FDC inhaler therapy during their baseline year; either ongoing prescriptions for FP-SAL with no change in ICS dosage or switch to efBDP-FOR at an ICS dosage equivalent to, or lower than, their last FP-SAL prescription $(\geq 2$ efBDP-FOR prescriptions) in their outcome year; and attended a practice in which five or more patients were switched from FP-SAL to efBDP-FOR within a three-month period. On this basis, 105,631 patients were excluded.

Even patients who met all other inclusion criteria but whose prescribed ICS dosage was increased at the index prescription date (IPD) were excluded. This step was taken in an effort to determine fairly whether efBDP-FOR was at least equivalent to FP-SAL when patients are switched as recommended by the NHS.,3 The study group was limited to the patients of primary care practices switching multiple patients from FP-SAL to efBDP-FOR over a short period of time, as this "wholesale" change in prescribing suggests that the switch was made for reasons other than clinical efficacy, such as lower ICS dosage for safety/tolerance and/or cost.
Of the remaining 77,500 patients under consideration, the final selection process included those who were between 18 and 80 years of age; had complete data for both the baseline and outcome years; whose smoking status was known; and who required no oral corticosteroids for maintenance during their baseline year. A total of 50,261 patients met these last inclusion criteria, of whom 390 were switched to efBDP-FOR and 49,871 remained on FP-SAL for the outcome year. Figure S2 illustrates the subsequent case matching process.

\section{Statistical analysis}

Exploratory data analysis was conducted for all variables of interest for both the baseline and outcome years. As a conservative approach, differences between treatment groups were considered possibly important if $p<0.10$. Variables meeting this criterion were examined for co-linearity and clinical importance to select those used as potential confounders (Box 2 ) in the regression modelling of outcomes.

\section{Data plots}

During exploratory data analysis, frequency distribution plots were generated to illustrate the distribution of variables measured on the interval or ratio scale and to determine whether categorisation was necessary (eg, if heavily skewed). Box plots were generated to illustrate the location and spread of the variable and identify potential outliers. Plots by treatment group were used to highlight baseline and outcome differences between treatment groups. For categorical variables, mosaic plots were generated to illustrate distributions and highlight baseline and outcome differences between treatment groups.

\section{Correlations}

Spearman correlation coefficients were calculated among all baseline variables to determine strengths of linear relationships between variables. Relationships with rank correlation coefficients $>0.30$ were considered, in conjunction with clinical interpretation, to identify pairings of variables that may present co-linearity issues at the modelling stage. Scatter plots and error bar plots were used to further investigate non-linear relationships.

\section{Predictive variables}

Multivariate analyses were conducted using the full dataset to identify baseline variables that were predictive $(p<0.05)$ of outcomes. These variables were then considered as potential confounders when modelling the outcome variables.

\section{Clinical outcomes, primary}

Exacerbation rates were compared across treatment arms using a conditional Poisson regression model. The model used empirical standard errors (for more conservative $\mathrm{Cl}$ estimations), and adjustments were made for potential baseline confounders. Variables that were significantly different - or showed a trend towards significance - between treatment groups at baseline were included as potential confounding factors. Variables that were found to be predictive $(p<0.05)$ of the outcome through multivariate analysis were also considered as potential confounders. 


\section{Clinical outcomes, secondary}

The adjusted odds of achieving risk domain asthma control (RDAC), overall asthma control (OAC), and treatment success (TS) were compared between matched treatment groups using conditional binary logistic regression models. For RDAC and OAC, asthma control status was used as the dependent variable, with treatment and potential confounding factors as explanatory variables. For TS, success status was used as the dependent variable, with treatment and potential confounding factors as explanatory variables.

The total number of exacerbations (clinical definition), hospitalisations (where event numbers were sufficient), and incidents of oral thrush were compared between treatment groups using a conditional Poisson regression model to obtain an estimate of relative exacerbation, hospitalisation, and incident rates. The model used empirical standard errors (for more conservative $\mathrm{Cl}$ estimations) and adjustments were made for potential baseline confounders.

The adjusted odds of being in a higher ICS adherence or SABA category were compared between matched treatment groups using conditional ordinal logistic regression models. The adherence or SABA category was used as the dependent variable, with treatment and potential confounding factors as explanatory variables.

Variables that were significantly different or showed a trend toward significance $(p<0.10)$ between treatment groups at baseline were included as potential confounding factors. In addition, variables that were found to be predictive $(p<0.05)$ of the outcome through multivariate analysis were also considered as potential confounders.

\section{Results}

Tables $3 \mathrm{~b}$ and $3 \mathrm{c}$ show other clinically important baseline variables for the matched treatment groups. Table $5 \mathrm{~b}$ provides full details of the secondary clinical outcome measures between matched treatment groups during the outcome year.

\section{References}

1. Ganderton D, Lewis D, Davies R, Meakin B, Brambilla G, Church T. Modulite: a means of designing the aerosols generated by pressurized metered dose inhalers. Respir Med 2002;96(Suppl D):S3-S8.

2. Homan K. Briefing paper: Primary care switch protocol-low and moderate dose ICS/LABA combination inhalers switch to Fostair 100/6 inhaler (bulletin on the internet). Cambridge: NHS East of England, June 2011. Available from http://www.see.nhs.uk/content/file/GP\%20Zone/Medicine\%20management/QOF/ nhalers/129-bulletin-5.pdf (accessed 4 May 2013).

3. Homan K. Primary care switch protocol-stepping down high dose ICS/LABA inhalers in asthma patients to moderate dose ICS/LABA inhalers including a switch to Fostair ${ }^{\circledR}$ 100/6 inhaler (bulletin on the internet). Cambridge: NHS East of England, July 2011. Available from http://www.clingov.eoe.nhs.uk/prescqipp/index.php/ prescribing/prescqipp-bulletins (accessed 4 May 2013). 
Figure S1. CONSORT diagram of patient selection for the Real-world Effectiveness in Asthma therapy of Combination inHalers (REACH) study. *An event comprised a repeat prescription for FP-SAL. Each repeat prescription was counted as a separate event, so patients may have had multiple events. This step was taken to ensure that enough eligible patients prescribed ongoing FP-SAL therapy were available so that each qualified efBDP-FOR patient could be closely matched with three unique FP-SAL patients (see Figure S2)

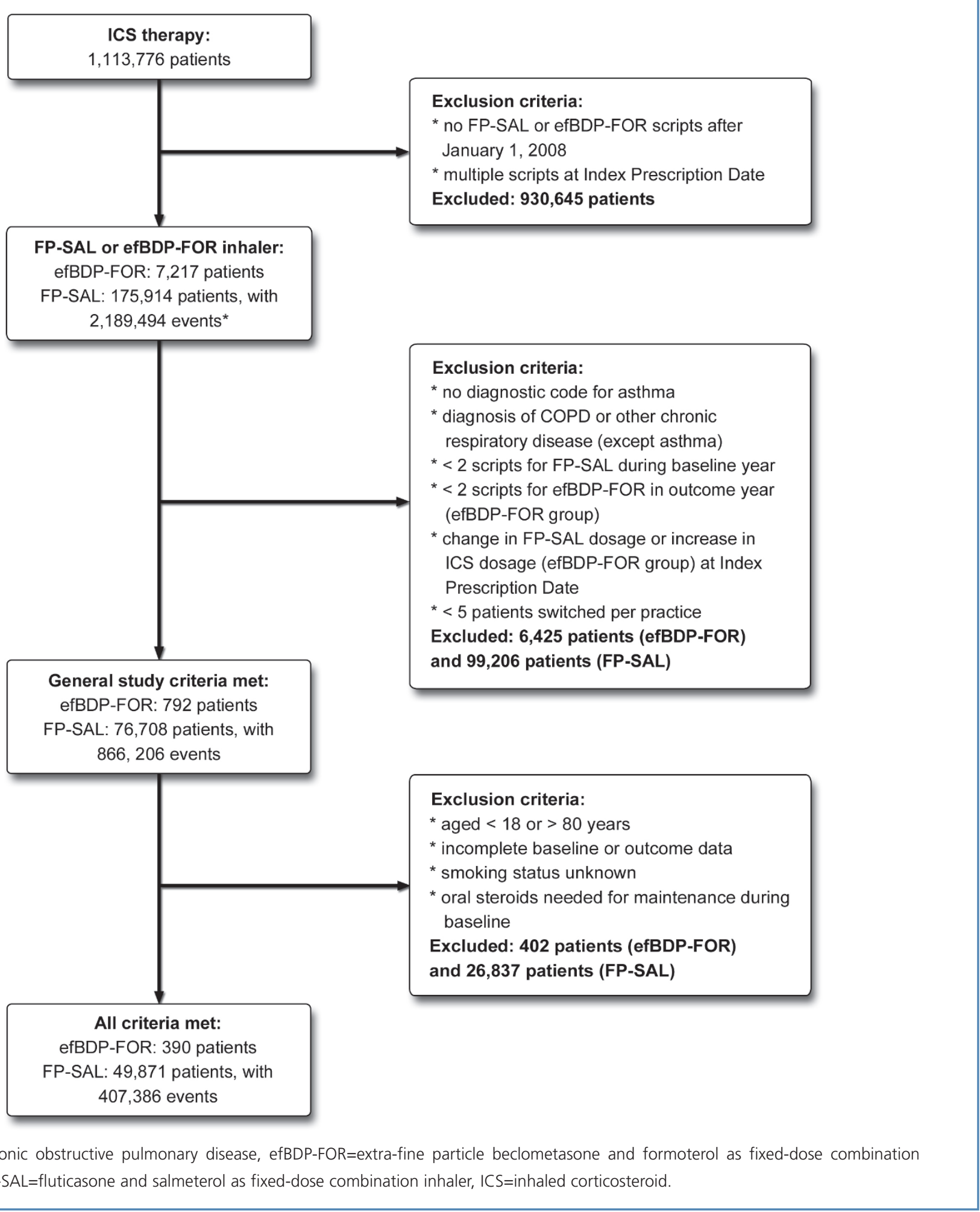


Figure S2. CONSORT diagram of patient matching for the Real-world Effectiveness in Asthma therapy of Combination inHalers (REACH) study. *An event comprised a repeat prescription for FP-SAL (see explanation in Figure S1)

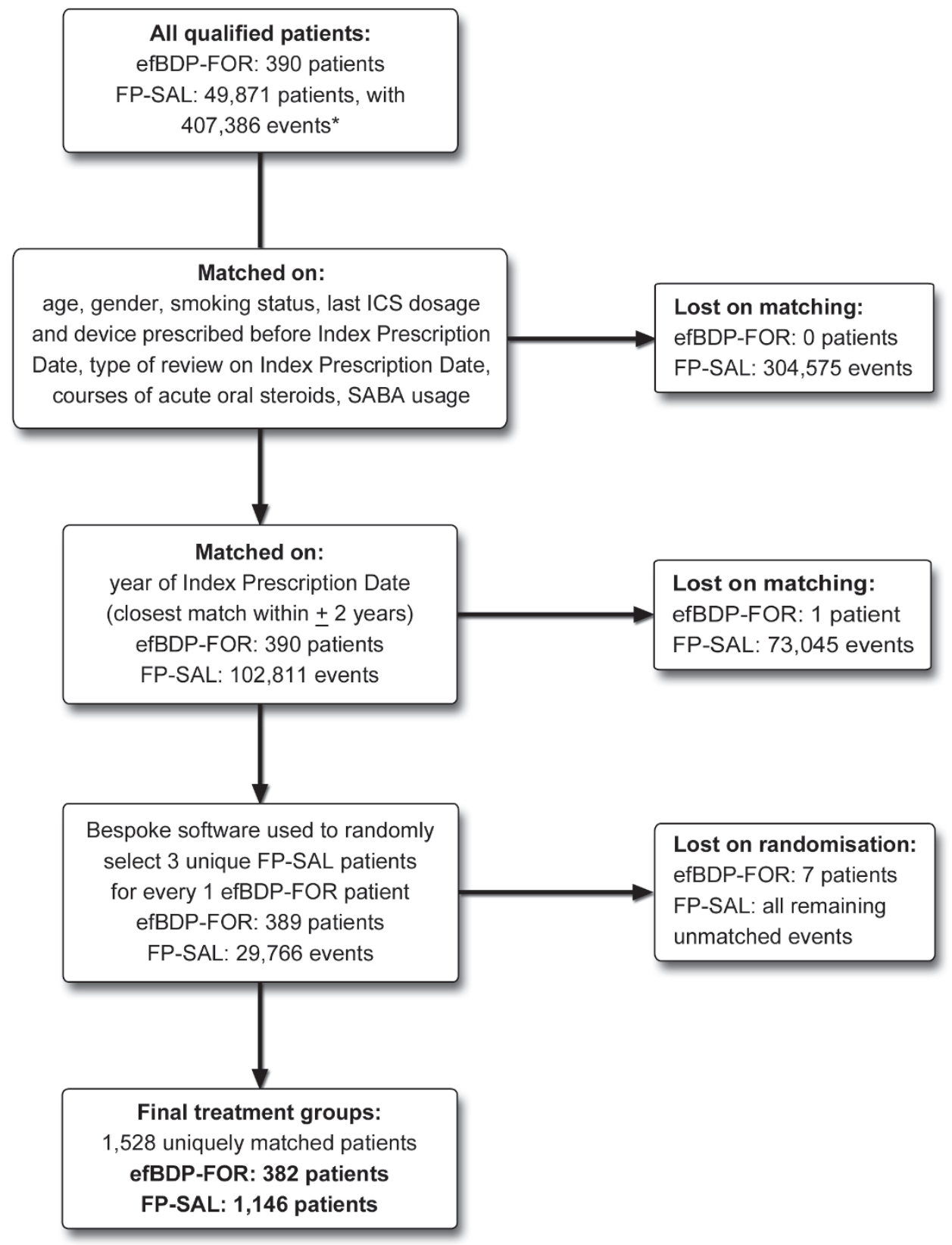

efBDP-FOR=extra-fine particle beclometasone and formoterol as fixed-dose combination inhaler, FP-SAL=fluticasone and salmeterol as fixed-dose combination inhaler, ICS=inhaled corticosteroid, SABA=short-acting $\beta_{2}$-receptor agonist. 
Box 2. Potential confounders examined in the initial analysis

Potential confounders examined at (or closest to) the index prescription date (IPD):

- Age

- Gender

- Height

- Weight

- Body mass index (BMI) (where BMI can be evaluated)

- Lung function, as indicated by \% predicted peak expiratory flow (calculated using age-specific equations for patients 18 years of age and those over 18 years $\left.{ }^{2}\right)$

- Smoking status

Potential confounders examined regardless of when they occurred relative to the IPD:

- Date of first asthma diagnosis

- Other respiratory or confounding diagnoses, including o Rhinitis

- Gastroesophageal reflux disease (GERD)

- Cardiac disease

o Eczema

Potential confounders examined in the year before the IPD:

- Presence/absence of co-morbid rhinitis (diagnosis ever and/or prescriptions for rhinitis therapy in the prior/outcome year)

- Presence/absence of co-morbid eczema (diagnosis ever and/or prescriptions for eczema therapy in the prior/outcome year)

- Presence of GERD (diagnosis ever and/or prescriptions for GERD therapy in the prior/outcome year)

- Other important unrelated co-morbidities using a modified Charlson Comorbidity Index ${ }^{3}$

- Number of exacerbations in year prior to the IPD

- Number of acute courses of oral steroids in the year prior to the IPD

- Number of hospitalisations for asthma/lower respiratory reasons or possibly asthma/lower respiratory-related (a non-specific hospitalisation code and an asthma/lower respiratory code within one week)

- Number of hospital outpatient attendances in the prior year where asthma and/or lower respiratory illness was the reason for referral

- Number of prescriptions for any antibiotic in the prior year where the reason for the prescription was lower respiratory tract infection

- Number of prescriptions for any respiratory therapy (split by number of prescriptions for each) in the prior year

- Other medications, number of prescriptions for the following in the year prior to the IPD

o Paracetamol

o Non-steroidal anti-inflammatory drugs (NSAIDs)

o Beta-blockers

o Theophylline

- Number of primary care consultations in the year prior

- Number of asthma consultations in the year prior

- Number of asthma consultations in the prior year that did not result in asthma exacerbation treatment

- Average short-acting $\beta_{2}$ agonist (SABA) daily dose (total combined dose of refilled prescriptions, averaged over 365 days)

- Number of SABA prescriptions received in the prior year

- Average inhaled corticosteroid (ICS) daily dose during the prior year (total combined dose of refilled prescriptions, averaged over 365 days)

- Adherence to ICS therapy (see Table 2 in main text)

- Spacer use/prescription

- Oral thrush

1. Rosenthal M, Cramer D, Bain SH, Denison D, Bush A, Warner JO. Lung function in white children aged 4 to 19 years. II. Single breath analysis and plethysmography. Thorax 1993;48(8):803-08.

2. Roberts CM, MacRae KD, Winning AJ, Adams L, Seed WA. Reference values and prediction equations for normal lung function in a non-smoking white urban population. Thorax 1991;46(9):643-50.

3. Aylin $P$, Bottle A, Jen MH, Middleton S. HSMR mortality indicators (article on the internet). London: Doctor Foster Research, 26 Nov 2010. Available online from http://www.drfosterhealth.co.uk/docs/HSMR?methodology?Nov?2010.pdf (accessed 15 March 2013).
Table 3b. Clinically important baseline variables in matched treatment groups: primary and secondary outcome measures

\begin{tabular}{|c|c|c|c|}
\hline Variable & $\begin{array}{l}\text { FP-SAL } \\
(n=1,146)\end{array}$ & $\begin{array}{l}\text { efBDP-FOR* } \\
(n=382)\end{array}$ & p Value \\
\hline \multicolumn{4}{|c|}{ Severe exacerbation rate (ATS/ERS definition) } \\
\hline 0 & $928(81.0 \%)$ & $312(81.7 \%)$ & 1.000 \\
\hline 1 & $149(13.0 \%)$ & $46(12.0 \%)$ & \\
\hline $2+$ & $69(6.0 \%)$ & $24(6.3 \%)$ & \\
\hline Mean (SD) & $0.29(0.76)$ & $0.34(1.13)$ & 0.112 \\
\hline Median (IQR) & $0(0,0)$ & $0(0,0)$ & \\
\hline \multicolumn{4}{|c|}{ Risk domain asthma control } \\
\hline Controlled & $761(66.4 \%)$ & $260(68.1 \%)$ & 0.415 \\
\hline \multicolumn{4}{|l|}{ Overall asthma control } \\
\hline Controlled & $389(33.9 \%)$ & $135(35.3 \%)$ & 0.297 \\
\hline \multicolumn{4}{|c|}{ Severe exacerbation rate (clinical definition) } \\
\hline 0 & $782(68.2 \%)$ & $263(68.8 \%)$ & 0.816 \\
\hline 1 & $237(20.7 \%)$ & $79(20.7 \%)$ & \\
\hline $2+$ & $127(11.1 \%)$ & $40(10.5 \%)$ & \\
\hline Mean (SD) & $0.51(0.94)$ & $0.55(1.26)$ & 0.286 \\
\hline Median (IQR) & $0(0,1)$ & $0(0,1)$ & \\
\hline \multicolumn{4}{|c|}{ Inpatient asthma-related hospitalisations } \\
\hline 0 & $1,138(99.3 \%)$ & $381(99.7 \%)$ & 0.355 \\
\hline $1+$ & $8(0.7 \%)$ & $1(0.3 \%)$ & \\
\hline \multicolumn{4}{|l|}{ Adherence to ICS therapy } \\
\hline$<50 \%$ & $231(20.2 \%)$ & $70(18.3 \%)$ & 0.282 \\
\hline $50-69 \%$ & $237(20.7 \%)$ & $76(19.9 \%)$ & \\
\hline $70-99 \%$ & $415(36.2 \%)$ & $142(37.2 \%)$ & \\
\hline $100+\%$ & $263(22.9 \%)$ & $94(24.6 \%)$ & \\
\hline Mean (SD) & $82.0(40.5)$ & $82.6(34.1)$ & 0.783 \\
\hline Median (IQR) & $80(54,99)$ & $81(57,99)$ & \\
\hline \multicolumn{4}{|l|}{ Incidence of oral thrush } \\
\hline Diagnosis & $5(0.4 \%)$ & $3(0.8 \%)$ & 0.421 \\
\hline $\begin{array}{l}\text { Diagnosis or antifungal } \\
\text { therapy }\end{array}$ & $20(1.7 \%)$ & $10(2.6 \%)$ & 0.295 \\
\hline \multicolumn{4}{|c|}{ All values are $n(\%)$ unless otherwise stated. } \\
\hline \multicolumn{4}{|c|}{$\begin{array}{l}\text { *These patients were on FP-SAL during their baseline year but were switched } \\
\text { to efBDP-FOR at the index prescription date. } \\
\text { †Conditional logistic regression. }\end{array}$} \\
\hline \multicolumn{4}{|c|}{$\begin{array}{l}\text { ATS/ERS=American Thoracic Society and European Respiratory Society, } \\
\text { efBDP-FOR=extra-fine particle beclometasone and formoterol as } \\
\text { fixed-dose combination inhaler, FP-SAL=fluticasone and salmeterol as } \\
\text { fixed-dose combination inhaler, ICS=inhaled corticosteroid, IQR=interquartile } \\
\text { range, SD=standard deviation. }\end{array}$} \\
\hline
\end{tabular}




\begin{tabular}{|c|c|c|c|}
\hline Variable & $\begin{array}{l}\text { FP-SAL } \\
(n=1,146)\end{array}$ & $\begin{array}{l}\text { efBDP-FOR* } \\
(n=382)\end{array}$ & $\begin{array}{l}\mathrm{p} \\
\text { Value }^{+}\end{array}$ \\
\hline \multicolumn{4}{|l|}{ Co-morbidities } \\
\hline Rhinitis $\neq$ & $495(43.2 \%)$ & $143(37.4 \%)$ & 0.047 \\
\hline Cardiac disease & $178(15.5 \%)$ & $34(8.9 \%)$ & 0.001 \\
\hline \multicolumn{4}{|c|}{ Asthma consultations } \\
\hline 0 & $255(22.3 \%)$ & $53(13.9 \%)$ & $<0.001$ \\
\hline 1 & $500(43.6 \%)$ & $165(43.2 \%)$ & \\
\hline $2+$ & $391(34.1 \%)$ & $164(42.9 \%)$ & \\
\hline Mean (SD) & $1.43(1.38)$ & $1.70(1.44)$ & $<0.001$ \\
\hline Median (IQR) & $1(1,2)$ & $1(1,2)$ & \\
\hline \multicolumn{4}{|c|}{ Respiratory prescriptions (all scripts) } \\
\hline Mean (SD) & $11.0(7.4)$ & $13.2(8.6)$ & $<0.001$ \\
\hline Median (IQR) & $9(6,14)$ & $11(7,17)$ & \\
\hline \multicolumn{4}{|l|}{ ICS scripts } \\
\hline Mean (SD) & $6.2(3.4)$ & $7.5(3.3)$ & $<0.001$ \\
\hline Median (IQR) & $5(4,8)$ & $7(5,10)$ & \\
\hline \multicolumn{4}{|l|}{ SABA scripts } \\
\hline Mean (SD) & $3.8(3.7)$ & $4.5(4.6)$ & $<0.001$ \\
\hline Median (IQR) & $3(1,5)$ & $3(1,6)$ & \\
\hline \multicolumn{4}{|c|}{ Average daily ICS dosage ( $\mu \mathrm{g} /$ day) } \\
\hline $1-200$ & $295(25.7 \%)$ & $70(18.3 \%)$ & 0.015 \\
\hline $201-400$ & $409(35.7 \%)$ & $150(39.3 \%)$ & \\
\hline $401-600$ & $285(24.9 \%)$ & $111(29.1 \%)$ & \\
\hline $601+$ & $157(13.7 \%)$ & $51(13.3 \%)$ & \\
\hline Mean (SD) & $374.9(255.2)$ & $388.0(241.0)$ & 0.253 \\
\hline Median (IQR) & $329(197,493)$ & $329(206,493)$ & \\
\hline \multicolumn{4}{|c|}{ LRTI consultations resulting in antibiotic prescription } \\
\hline 0 & $916(79.9 \%)$ & $312(81.7 \%)$ & 0.520 \\
\hline 1 & $167(14.6 \%)$ & $50(13.1 \%)$ & \\
\hline $2+$ & $63(5.5 \%)$ & $20(5.2 \%)$ & \\
\hline Mean (SD) & $0.28(0.65)$ & $0.27(0.67)$ & 0.729 \\
\hline Median (IQR) & $0(0,0)$ & $0(0,0)$ & \\
\hline \multicolumn{4}{|c|}{ Controller-reliever ratio } \\
\hline$<0.5$ & $193(16.8 \%)$ & $48(12.6 \%)$ & 0.017 \\
\hline$\geq 0.5$ & $953(83.2 \%)$ & $334(87.4 \%)$ & \\
\hline
\end{tabular}

All values are $n(\%)$ unless otherwise stated.

*These patients were on FP-SAL during their baseline year but were switched to efBDP-FOR at the index prescription date.

tConditional logistic regression.

\#Rhinitis diagnosis or nasal spray use

efBDP-FOR=extra-fine particle beclometasone and formoterol as fixed-dose combination inhaler, $\mathrm{FDC}=$ fixed-dose combination inhaler,

FP-SAL=fluticasone and salmeterol as fixed-dose combination inhaler, ICS=inhaled corticosteroid, IQR=interquartile range, LRTI=lower respiratory tract infection, $S A B A=$ short-acting $\beta_{2}$-receptor agonist, $S D=$ standard deviation.

\section{Table 5b. Comparison of secondary outcomes between matched treatment groups during the outcome year}

\begin{tabular}{|c|c|c|}
\hline Outcome & $\begin{array}{l}\text { FP-SAL } \\
(n=1,146)\end{array}$ & $\begin{array}{l}\text { efBDP-FOR } \\
(n=382)\end{array}$ \\
\hline \multicolumn{3}{|l|}{ Risk domain asthma control } \\
\hline Controlled & $786(68.6 \%)$ & $277(72.5 \%)$ \\
\hline Adjusted odds ratio* $(95 \% \mathrm{CI})$ & 1.00 & $1.15(0.88$ to 1.52$)$ \\
\hline \multicolumn{3}{|c|}{ Overall asthma control (risk and impairment) } \\
\hline Controlled & $358(31.2 \%)$ & $149(39.0 \%)$ \\
\hline Adjusted odds ratiot (95\% CI) & 1.00 & $1.56(1.14$ to 2.14$)$ \\
\hline Also adjusted for BMI¥ $(95 \% \mathrm{Cl})$ & 1.00 & $1.53(1.10$ to 2.11$)$ \\
\hline \multicolumn{3}{|c|}{ Severe exacerbation rate (clinical definition) } \\
\hline 0 & $812(70.9 \%)$ & $280(73.3 \%)$ \\
\hline 1 & $211(18.4 \%)$ & $62(16.2 \%)$ \\
\hline $2+$ & $123(10.7 \%)$ & $40(10.5 \%)$ \\
\hline Adjusted rate ratio§ $(95 \% \mathrm{Cl})$ & 1.00 & $1.01(0.80$ to 1.29$)$ \\
\hline \multicolumn{3}{|l|}{ Treatment success } \\
\hline Successful & $727(63.4 \%)$ & $263(68.8 \%)$ \\
\hline Adjusted odds ration $(95 \% \mathrm{Cl})$ & 1.00 & $1.24(0.95$ to 1.62$)$ \\
\hline \multicolumn{3}{|l|}{ Average daily SABA usage $(\mu \mathrm{g})$} \\
\hline 0 & $173(15.1 \%)$ & $55(14.4 \%)$ \\
\hline $1-100$ & $325(28.4 \%)$ & $128(33.5 \%)$ \\
\hline $101-200$ & $320(27.9 \%)$ & $90(23.6 \%)$ \\
\hline $201-400$ & $252(22.0 \%)$ & $91(23.8 \%)$ \\
\hline $401+$ & $76(6.6 \%)$ & $18(4.7 \%)$ \\
\hline Adjusted odds ratio** $(95 \% \mathrm{Cl})$ & 1.00 & $0.74(0.60$ to 0.91$)$ \\
\hline \multicolumn{3}{|l|}{ Adherence to ICS therapy (\%) } \\
\hline$<50$ & $314(27.4 \%)$ & $79(20.7 \%)$ \\
\hline $50-69$ & $174(15.2 \%)$ & $53(13.9 \%)$ \\
\hline $70-99$ & $377(32.9 \%)$ & $131(34.3 \%)$ \\
\hline $100+$ & $281(24.5 \%)$ & $119(31.1 \%)$ \\
\hline Odds ratio $(95 \% \mathrm{Cl})$ & 1.00 & $1.40(1.13$ to 1.73$)$ \\
\hline \multicolumn{3}{|c|}{ Inpatient asthma-related hospitalisations } \\
\hline $1+$ & $28(2.4 \%)$ & $7(1.8 \%)$ \\
\hline Adjusted rate ratio†† $(95 \% \mathrm{Cl})$ & 1.00 & $0.67(0.30$ to 1.49$)$ \\
\hline \multicolumn{3}{|l|}{ Incidence of oral thrush } \\
\hline $1+$ & $29(2.5 \%)$ & $16(4.2 \%)$ \\
\hline Adjusted rate ratio $\neq \neq(95 \% \mathrm{Cl})$ & 1.00 & 1.59 (0.77 to 3.27$)$ \\
\hline
\end{tabular}

Values are $n(\%)$ unless otherwise stated.

*Adjusted for baseline confounders: (consultations for LRTIs resulting in a course of antibiotics (categorised), allergy prescriptions (categorised), and asthma-related Outpatient Department attendance (yes/no).

†Adjusted for: rhinitis diagnosis and/or therapy (yes/no), cardiac disease diagnosis (yes/no), asthma consults with no oral steroid script (categorised), SABA scripts (categorised), single inhaler ICS use (yes/no), and LRTI consults resulting in antibiotics (categorised).

‡BMl: body mass index (categorised).

$\S$ Adjusted for: acute oral steroids (categorised), LRTI consults resulting in antibiotics (categorised), allergy scripts (categorised), and asthma consults (categorised). IAdjusted for: asthma consults with no oral steroid script (categorised), SABA scripts (categorised), and allergy scripts (categorised).

**Adjusted for: asthma consults (categorised), scripts for separate ICS inhalers (yes/no), and SABA scripts (categorised).

$\dagger †$ Adjusted for: primary care consults (categorised).

¥¥Adjusted for: asthma consults (categorised), non-asthma-related consults (categorised), and baseline incidence of oral thrush (yes/no).

$\mathrm{Cl}=$ confidence intervals, efBDP-FOR=extra-fine particle beclometasone and formoterol as fixed-dose combination inhaler, FP-SAL=fluticasone and salmeterol as fixed-dose combination inhaler, ICS=inhaled corticosteroid, LRTI=lower respiratory tract infection, $\mathrm{SABA}=$ short-acting $\beta_{2}$-receptor agonist. 